\title{
On the Cultivation of Middle School Students' Creativity
}

\author{
Shiqi Gong ${ }^{1}$ \\ ${ }^{1}$ Jiangxi Normal University, China \\ Correspondence: Shiqi Gong, Jiangxi Normal University, China
}

Received: December 1, 2019

Accepted: December 21, 2019

Online Published: December 23, 2019

doi: $10.5539 /$ elt.v13n1p134

URL: https://doi.org/10.5539/elt.v13n1p134

\begin{abstract}
This paper first explains the concept of creativity, then reviews the domestic and foreign researches on creativity, and then discusses the importance and basic principles of cultivating creativity of middle school students. Finally, the paper puts forward the ways to cultivate the creativity of middle school students. The purpose of this paper is to promote the development of the teaching theory and the renewal of the teaching concept so as to develop the creative teaching and research learning and further improve the quality education level.
\end{abstract}

Keywords: cultivating the creativity of middle school students, importance, principle

\section{Introduction}

This paper is divided into five section. Section 1 introduces the concept of creativity, including creative products, creator characteristic, creative process and creative environment. Section 2 introduces previous studies on creativity at home and abroad. Section 3 tells about the importance of cultivating creativity. Section 4 introduces the basic principles of cultivating the creativity of middle school students. And then the author gives suggestions on how teachers should improve the creativity of students. Finally, conclusion is made and limitation of this paper is proposed. All in all, this paper adds the value to the existing literature on how to cultivate middle school students' creativity.

\section{The Concept of Creativity}

Compared with other fields of scientific research, creativity is a very young science. At the same time, the concept of creativity is very difficult to define. (Amabile, 1988). Therefore, different researchers have different views on the definition of creativity according to different research orientations. Rhodes (1961) proposed 4P for the definition of creativity: creative products, high creator's personality, process of creation and press / place. Most of the relevant creativity researchers focus on these four definitions.

\subsection{Creative Products}

Stein (1953) believes that creativity is a kind of novel, lasting or practical product that can be satisfied and accepted by the group. Perkins (1988) thinks that creativity should contain the following two meanings: (1) the result of creativity should be original and appropriate (2) creative people are people who constantly produce creative products. Steimberg and Lubart (1996) believe that creativity is the ability to produce novel and appropriate products. Amabile (1997) believes that creative products must be novel, appropriate, useful, correct and valuable.

To sum up, creative individuals are bound to produce creative products, so products can be used to evaluate whether they are creative. According to the definition of creative products by foreign scholars, the creative output must include the creative level of uniqueness and novelty, and also conform to the external evaluation criteria, that is, the applicable and valuable practical level. That is to say, the first condition of creativity is originality, novelty. At the same time, we must emphasize the applicability and value of solving problems.

\subsection{Creator Characteristics}

Guilford (1968) proposed that creativity is a kind of divergent thinking ability, which has five different characteristics: (1) Sensitivity: the sensitivity of being aware of a problem or situation. (2) Fluency: the ability to generate ideas, ideas and solutions. (3) Flexibility: the ability to see problems from different perspectives without being constrained by habits. (4) Originality: the ability to generate unusual ideas, opinions or plans. (5) Refinement (elaboration): refers to the increase in original ideas and concepts. Torrance (1962) thought that creativity is the ability to solve unknown problems, form a new hypothesis for the problem, revise or retest the 
hypothesis to solve the problem. Sternberg and Lubart (1997) believed that the personality traits of creative people should be risk takers, who do not follow the opinions of others and have their own ideas. Amabile (1988) put forward ten individual characteristics related to creativity: high self motivation, special cognitive ability, risk-taking orientation, professional knowledge and experience, quality of members of the group, rich experience, high social ability, intelligence and unbiased and unconventional attitude. Sternberg (1988) put forward six characteristics of creativity: endure ambiguous situations, be willing to overcome obstacles, be willing to self grow, be motivated by intrinsic motivation, moderate risk recipients, desire to be affirmed and be willing to work for being affirmed.

\subsection{Creative Process}

The view of creative process focuses on the process of creative activities. Wallas (1926) put forward four steps in the process of creation: first, preparation period: combining the old and new knowledge and experience of individuals, collecting information on relevant issues. Second, gestation period: in the bottleneck period, put the problem aside and leave it alone. At the same time, the individual subconscious is still thinking about how to solve the problem. Third, the period of suddenly enlightened: suddenly realizing the key to the solution of the problem. Fourth, Validation period: implement and verify the solutions realized in the previous step. Torrance (1988) put forward four stages of creative thinking: first, detect problems or difficulties; second, put forward guesses and hypotheses; third, evaluate and verify hypotheses; fourth, communicate results.

\subsection{Creative Environment}

In the 1980s, scholars began to question the traditional individual oriented research and thought that it paid too much attention to human factors, so they began to focus on the impact of external environmental factors on creativity. Torrance (1975) proposed that the family, the social composition and the living environment of the school have a profound impact on the development of individual creativity. Mellou (1996) believes that creativity is influenced by the environment, such as company contact, parents' permission and enough time and space. Amabile (1988) called for the study of creativity in the form of social psychology and the development of "social psychology of creativity", and believed that environmental factors have a great influence on creativity. Runco and Walberg (1998) took 143 researchers as subjects. The results showed that creativity was not only influenced by personality traits, knowledge level, cognitive ability and other aspects, but also by external environmental factors such as education, culture, society and family. In a word, the creator starts from creation. It is closely related to the supportive environment: family, school and society.

\section{Literature Review on Creativity at Home and Abroad}

\subsection{Previous Studies on Creativity at Home}

Some Chinese scholars have made some attempts to examine creativity of Chinese students. However, most of these research focus on how to develop creativity or divergent thinking of students in the first language context rather that EFL learning environment.

Li (1997) summarized the characteristics of students' creative thinking and their relations to creativity on the basis of creative thinking test of students at Southeast University. The main characteristics of students' creative thinking evaluated in the test were fluency, flexibility and elaboration. Generally speaking, marks of fluency and flexibility had direct relations to the general grade of creative thinking. Thus, it was important to train fluency and flexibility of thinking in order to develop students' creative thinking ability. Considering the characteristics of students' creative thinking and real situation of our education, it was necessary to develop students' creativity, particularly flexibility and fluency of thinking at universities of China. The author also suggested some new ways to facilitate students' creative thinking ability, such as self-comment and mutual-comment., debating., discussion on special items, exercise-correcting mutually and creativity-compensated examination.

Wen (1999) discussed the importance and necessity of paying attention to the development of thinking ability in oral teaching for College English majors, and puts forward suggestions on how to cultivate students' thinking ability in oral teaching. The cultivation of innovative thinking ability should run through the whole process of primary, secondary and university education. She claimed that it was essential to set up a course to develop students' creativity in educational reform.

Zeng (2000) aimed to touch upon one important aspect of education for all- around development for the English majors who have entered the 21th century, that is, enhancing the discipline of their dialectic and systematic thinking abilities, modes and techniques with which they can not only make a good use of theoretic knowledge of other relative sciences in studies of their own specialties but develop themselves into innovative and creative talents with all-around abilities. Moreover, the paper also discussed the issues on integrating scientific thinking 
discipline into textbook compiling, exercise-design and classroom activities in their junior as well as senior studying phases. Strengthening the training of subject thinking was one of the main ways to develop the mental potential of foreign language majors, and it was also a good form of quality-oriented education. The training of thinking skills can improve students' intelligence level, form a reasonable knowledge structure and improve their professional quality. The training of thinking ability and the teaching of subject knowledge are interdependent.

Zhang (2003) pointed out the necessity and importance of cultivating creative thinking ability in foreign language education. She deemed that the creative thinking ability in foreign language education should be the synthesis and flexible application of language ability, pragmatic ability and thinking ability, which was the dialectical unity of language and thinking. In the specific teaching activities, we should integrate the cultivation of thinking psychology and thinking quality, the training of thinking organs and thinking methods. Besides, she also provided practical suggestions for developing creative thinking in the EFL teaching. First of all, we should create a positive, active, equal, open and cordial atmosphere in class. Secondly, using teaching aids and game activities to train students' thinking organs. Thirdly, teachers should alternate training of image thinking and abstract thinking. Using various teaching methods to visualize the teaching content such as models, pictures, video materials and practical activities.

Zhang, He and Cui (2009) discussed the effect of self-access English learning ability on creativity. They suggested that teachers create situations by inducing students to think and seek answers from different angles and respect students' independent opinions. When students' opinions were wrong and biased, they were not eager to give negative evaluation, but guided students to find problems and correct the problems by themselves. It played an important role in the full development of students' personality and the cultivation of innovative spirit. Therefore, in this kind of divergent thinking training, it can not only cultivate students' innovative spirit but also improve students' practical ability.

$\mathrm{Wu}$ (2011) discussed the factors that affect the oral English output of vocational college students and the effect of English language environment on oral English output. She argued that developing creativity is the responsibility of basic education; curricular programs and discovery learning need to combine to stimulate the creativity of students.

An (2011) did a study on how to cultivate students' creativity. Through the implementation of the course of cultivating creative thinking and creative personality as the main content in the experimental group, the influence of the course on the creative thinking, creative personality and writing ability of junior high school students was investigated. The course content included the activities of cultivating middle school students' self-awareness, creative thinking and creative personality, and it adopted the form of group discussion, role-playing, games and others. The main feature of the course was to cultivate students' creative personality so as to give full play to their initiative and enthusiasm, let them find out the joy and significance of creation. The author also gave some suggestions on how to conduct divergent thinking tasks in middle school students' writing course.

Ni (2012) introduced the connotation and classification of bilinguals' creativity, and combed out the relevant factors that affect the bilinguals' Creativity: the level of second language, the age of acquiring second language, the amount of second language contact, teaching content and individual characteristics. It was concluded that bilinguals with high level of second language, early acquisition of second language, large amount of second language contact, reasonable choice of teaching content and good personality characteristics had more obvious advantages in creativity

$\mathrm{Xu}$ (2013) attempted to explore the relationship between creativity and the oral communicative competence of the Chinese EFL learners. The findings revealed that there existed the significant relationship between creativity and the oral communicative competence of Chinese students.

\subsection{Previous Studies on Creativity Abroad}

Comparatively, the research accomplishment on creativity abroad is more booming and prosperous.

Sternberg (1985) argued that high creativity students or the students who were placed in the creative encouragement condition performed better than those who have been identified as creative but not placed in such a condition.

Otto (1998) carried out a small-scale study of the effects of learners' creativity on language learning. In this study, the creativity test was made up of five subtasks (consequences, unusual uses, common problems, categories, and associations). He found out that there existed the positive relationship between the students' total scores on the creativity test and their English grades. To be specific, the scores on the separate tasks were all significantly related to language learning success. That is, creativity could be observed in general outcomes of the EFL 
learning.

Hadley (2003) suggested that creativity played a remarkable role in the EFL learning and language use creatively. He maintained that learners, who wanted to make progress in their skills beyond the elementary phases, must learn to create with the language, or in other words make use of language creatively.

Albert and Kormos (2004) carried out an exploratory study to examine the effect of creativity on second language oral task performance. They indicated that different aspects of creativity might affect the amount of output students produce but not on the quality of narrative performance. What's more, creativity had a moderate influence on the output of students in narrative tasks.

Hajilou et al (2012) aimed to determine the relationship between creativity and lexical reception, creativity and production knowledge of Iranian EFL students. The results demonstrated that there was not a high correlation between creativity on one hand and lexical reception and production on the other hand. The learners' passive and active vocabulary knowledge in the tests as a whole and at different word-frequency level were highly correlated. Passive vocabulary was always larger than active vocabulary at all levels; however, the gap between the two increased at lower word-frequency level.

Fatemeh Seddigh (2013) tried to explore the relationship between Iranian EFL students' creativity and their use of vocabulary learning strategies. Also, he attempted to find out if gender played any role in this relationship. For measuring the creativity of a group of 101 medical students at Shiraz University of Medical Sciences, the Torrance Test of Creative Thinking was conducted. Subsequently a vocabulary learning strategies. Questionnaire was given to the participants to identify their vocabulary learning strategies employment. The results revealed that the participants possessed a high level of creativity but there was no significant difference in this regard according to gender. A significant correlation was found between creativity and the overall vocabulary learning strategies use of female students, but not for males. However, the correlation observed between creativity and the overall vocabularies learning strategies use of the participants was statistically significant in general

\section{The Importance of Cultivating Creativity}

\subsection{Cultivating Creativity is the Key to Realize the Goal of Modern Education}

Deng Xiaoping once said, "Education should face the world, the future and modernization,". Its purpose is to cultivate a large number of talents in line with the development of modern society in China. It can be seen that we need to put the cultivation of human creativity in the first place and advocate creative education. Creative education believes that education is a complex system engineering. The cultivation of creative talents should start from childhood. In the basic education stage, we should focus on stimulating the creative desire. In the middle school stage, we should focus on the cultivation of students' psychological quality of creative learning, the cultivation of students' creative problem-solving ability, and the provision of a creative learning environment. The lack of creative education will not only strangle the creativity of students and exert a bad influence on them, but also it is beyond the needs of modern society. Therefore, in the middle school education and teaching, we should always take the cultivation of middle school students' creativity as the goal, and actively encourage students to be creative.

\subsection{Cultivating the Creativity of Middle School Students is the Basic Requirement of Quality Education in China}

The basic requirement of quality education is to make the students develop comprehensively in morality, intelligence, physique, beauty, labor, etc., and improve their comprehensive quality constantly. Creativity is the highest quality of human beings. Obviously, cultivating the creativity of middle school students meets the basic requirements of quality education in China. However, due to the influence of traditional education and teaching concepts, the middle school education in China has not really changed from "examination-oriented education" to "quality-oriented education". This has seriously restricted the development of individual students and the development of creative potential. If we don't change it as soon as possible, it will directly affect the quality of the trained talents, the process of modernization, and make our country in a very unfavorable situation in the fierce international competition. In order to reverse this situation and keep up with the pace of the times, we must advocate quality education and innovative education.

\subsection{Middle School Stage is the Best Time to Cultivate Creativity}

Middle school stage is the most rapid developmental period of middle school students' in imagination and thinking. As far as the development of imagination is concerned, first, intentional imagination is the main position; second, imagination tends to be realistic; third, creative imagination is increasingly dominant. In terms of the development of thinking, on the one hand, the thinking ability of middle school students develop rapidly and the abstract logical thinking is in the dominant position; on the other hand, the dominant abstract logical 
thinking is gradually transiting from the empirical type to the theoretical type.

In short, middle school stage is the golden age of creativity. Because middle school students have learned certain knowledge and accumulated certain experience in this period, while knowledge and experience are the necessary conditions for the development of creativity. What's more, middle school students have very good quality of creativity, they are energetic, keen in observation, strong in memory, thoughtful, imaginative, brave in exploration, innovative, adventurous and yearning for truth. Most importantly, there is no preconceived thinking mode obstacle that hinders the creation of innovation consciousness, students are not easy to be bound by old ideas and old culture, and dare to challenge the old traditional authority.

\section{The Basic Principles of Cultivating the Creativity of Middle School Students}

\subsection{Combination of Knowledge Transfer and Skill Training}

The mastery of basic knowledge is the basis of skill formation. Correct basic knowledge is helpful to improve the accuracy and the speed of skill formation. Skill is the ability to apply knowledge. If there is no knowledge as the basis, skills will become water without source and wood without foundation. However, the understanding of corresponding knowledge is not equal to the formation of skills.

The acquisition of any advanced and complex scientific knowledge is inseparable from the skills of listening, speaking, reading and writing formed in the basic education stage. Therefore, knowledge and skills influence and promote each other. Knowledge and skills are the basis of people's creativity. If we want to cultivate the creativity of middle school students, we must pay attention to the "double base" education and combine the knowledge imparting with the skill training. On the one hand, we should pay attention to the teaching of basic knowledge. Because basic knowledge has wide applicability, the mastery of basic knowledge is conducive to learning relevant professional technology and understanding new knowledge of the same kind. In addition, it is helpful to solve new problems and develop students' intelligence and ability. On the other hand, we should be strict with basic skill training. According to the law of skill formation, teachers should train students strictly and repeatedly, so that students can form accurate and proficient skills.

\subsection{Combination of Intelligence Training and Non-Intelligence Training}

Intelligence is a psychological operating system that marks the developmental level of an individual's reflecting system. It is mainly composed of five basic factors: attention, observation, memory, imagination and thinking. Non-intelligence factors refer to all psychological factors other than intelligence. It mainly includes emotion, will, personality and so on. It can be seen that intelligence and non- intelligence are closely related, mutually conditioned and mutually promoted. The development of intelligence needs the support of non-intelligence, so as to promote the development of non-intelligence; the development of non- intelligence can also make intelligence get corresponding development, and play a compensation role for intelligence. Intelligence and non-intelligence factors are the necessary conditions for people to create. If we want to cultivate the creativity of middle school students, we must combine the intelligence training with the non-intelligence training, for creativity is influenced by both of them.

\subsection{Combination of Concentrated Thinking Training and Divergent Thinking Training}

Concentrated training is the aggregation of all kinds of information provided by the problem to get a correct answer or the best solution. Divergent thinking is a kind of thinking along different directions, to explore new prospects and to pursue diversity. From primary school to high school, the training of concentrated thinking is gradually strengthened. It is true that there is nothing wrong with this. However, the training of divergent thinking has not kept up with it, which is very unfavorable to the cultivation of middle school students' creative thinking. In the basic education stage of absorbing knowledge, the effective combination of concentrated thinking training and divergent thinking training should be used to better absorb knowledge and develop thinking ability.

\subsection{Combination of Thinking Training and Operation Training}

Thinking training is to improve people's thinking ability, and operation training is to improve people's operation ability. The so-called thinking ability refers to the comprehensive ability composed of comprehension, analysis, synthesis, comparison, generalization, abstraction, reasoning, argumentation, judgment, expression, etc. that individuals show in learning, cognition, speaking, operation and other practical activities. The so-called operation ability is the "operation ability". Thinking ability and operation ability are necessary for people to engage in creative activities, because creative activities are purposeful and conscious practical activities. If we want to cultivate the creativity of middle school students, we must combine thinking training with operation training. 
The above four principles are interrelated and inseparable. Among them, knowledge and skills are the basis for people to engage in creative activities; intelligence and non-intelligence are the guarantee to acquire knowledge and skills, and also the necessary conditions for people to engage in creative activities; the combination of concentrated thinking training and divergent thinking training is conducive to the cultivation of people's creative thinking, which is not only the constituent element of intelligence, but also the core of creativity. Thinking is the core of intelligence, operation is the manifestation of thinking. Creativity, as a practical ability, are always inseparable from thinking and operation. Therefore, we must combine these four principles organically when cultivating the creativity of middle school students.

\section{Implication}

\subsection{Middle School Teachers having a Creative Education Concept is the Prerequisite of Creativity Training}

As the spokesman of the society, the influence of teachers on students is self-evident. On the one hand, teachers' attitudes or ideas will have an impact on students' motivation, thus affecting students' intellectual input in creative activities; on the other hand, students' experience in the process of following teachers will have an important impact on their next learning activities. At present, the basic education curriculum reform is in full swing, but the current situation of middle school students' creativity development is still worrying. Therefore, it is of vital importance to prepare future teachers with creative consciousness.

\subsection{Forming a Characteristic Creativity Training Mode according to the Time and Local Conditions}

For the creation of education model, first of all, it is not a fixed framework, it is open, dynamic, developmental and complex. Teachers should enrich themselves and improve themselves. As the basic requirement of teachers, it is also necessary in the process of cultivating students' creativity. If there is no extensive and profound knowledge to rely on, teachers are unable to study how to cultivate students' creativity and other issues. Secondly, if there is no definite teaching method, it is better to adapt to it and give full play to the creativity of teachers. There is no absolutely flawless creative education mode. Therefore, it is not necessary for teachers to apply the established creative education model. Teachers should develop a creative training mode suitable for our students according to their own characteristics. Lastly, teachers should absorb the beneficial results of current creativity research and promote the reform of education and teaching in combination with the actual situation. At present, the theoretical research of creativity is increasingly rich, which lays a good foundation for teachers to choose the right theory. With the continuous revision and improvement of many theories, the guidance of the theory to the cultivation of creativity is constantly enhanced. Learning from the existing research results, we can get inspiration through the study of these theories, so that we can better develop the creativity of students.

\subsection{Paying Equal Attention to both Creative Personality and Cognition of Middle School Students is Conducive to Cultivate Creativity}

Firstly, teachers should create a creative atmosphere. It is an important to stimulate students' creative motivation so that students can better use creative knowledge and skills for creative activities. Secondly, teachers should integrate different subjects to improve students' knowledge, skills and interest. Last but not least, enabling students to learn to pay attention to the development of others and society. The importance of team learning and team creativity is a necessary way of cooperation in the era of knowledge economy. In creative education, we should encourage students to cooperate, cultivate students' cooperative ability, and lay a foundation for their future development. In addition, in order to make students adapt to the society better and become creative individuals beneficial to the development of human society, we should also pay special attention to the cultivation of students' sense of social responsibility, moral awareness and legal awareness.

\section{Conclusion}

Creativity is the ability to produce work that is both novel. It is through creativity that we can cope with significant challenges in our environments in novel and appropriate ways. Indeed, given the rate at which the world is changing, the importance of creativity to our lives is likely to increase. And certainly it is important for success in almost any occupation that requires thinking, whether it be as an artist, writer, scientist, business person, sales person, teacher, or whatever. Therefore, it is of vital importance for teachers to cultivate students' creativity. Since this study is quite limited, many future researches are expected to depict a more detailed and complete picture of creativity, one important yet inadequately investigated individual variable almost in all walks of life, in the EFL context of China 


\section{References}

Albert A, Kormos. (2004). J. Creativity and narrative task performance, An exploratory study. Language learning, 54(2), 277-310. https://doi.org/10.1111/j.1467-9922.2004.00256.x

An min (2011). Training Activities and Experiments of Junior High School Students' Creativity. Nanjing Normal University.

GaoJingwen, Zhujingcai. (1982). Creation and Teaching. Zhonghua Publishing House.

Hadley, A.O. (2003). Teaching Language in Context. (3rd ed.). Massachusetts, Heinle \& Heinle Publishers.

Hajilou Y, Yazdani H \& Shokrpour N. (2012). The Relationship between Iranian EFL Learners' Creativity and Their Lexical Reception and Production Knowledge. English Language Teaching, 5(3), 131-146. https://doi.org/10.5539/elt.v5n3p131

Jiafuming. (1976). Education for Talents. Kaiming Bookstore.

Jiazeng L \& Yanbao L, Yi C. (1997). Evaluating of creative thinking of students and creativity development at Southeast University, China. Proceedings Frontiers in Education 1997 27th Annual Conference. Teaching and Learning in an Era of Change. IEEE, 1, 576-579.

Lu xuemei. (1990). Creative Personality Traits. Creative Thinking Education.

Ni Chuangbing. (2012). A Review on the Influencing Factors and Mechanism of Bilinguals' Creativity. Foreign Language Teaching and Research, Bimonthly Journal of Foreign Languages, 44(3), 411-423.

Ottó I. (1998). The relationship between individual differences in learner creativity and language learning success. TESOL quarterly, 32(4), 763-773. https://doi.org/10.2307/3588011

Seddigh F \& Shokrpour N. (2013). Creativity and its relationship with vocabulary learning strategy use of EFL students. Journal of Studies in Education, 3(2), 139-151. https://doi.org/10.5296/jse.v3i2.3199

Su Fangliu. (1990). Skills to Enhance Creativity. Creative Thinking Education.

Wen qiufang (1999). Oral English Teaching and the Cultivation of Thinking Ability. Foreign Language Teaching Theory and Practice, (2), 1-4.

Wu xiaoqing. (2011). On the Factors Influencing Students' Language Output. Brand, 2, 73-74.

Xu jiajin. (2013). A Study of Discourse Assessment in Chinese Learners' Oral English Narration. Foreign Language Teaching and Research, Bimonthly Journal of Foreign Languages, (1), 69-79.

\section{Copyrights}

Copyright for this article is retained by the author(s), with first publication rights granted to the journal.

This is an open-access article distributed under the terms and conditions of the Creative Commons Attribution license (http://creativecommons.org/licenses/by/3.0/). 